\title{
COLLECTING BIRDS AND CONSERVATION
}

by L. L. Snyder, Curator, Department of Ornithology, Royal Ontario Museum

Reprinted from THE ONTARIO FIELD BIOLOGIST, \#12, 1958. 


\title{
COLLECTING BIRDS AND CONSERVATION
}

\author{
by L. L. Snyder, Curator, \\ Department of Ornithology, \\ Royal Ontario Museum
}

With the widening of interest in nature and a strengthening of conservation consciousness, there is a multiplication of persons giving local leadership. This is good providing that such leaders focus on fundamentals and do not emphasize the insignificant. Any social movement, philosophical or scientific, will suffer if fanaticism is prevalent. Conservationists who are more concerned about the sparrow's fall than ground-water levels and erosion should readjust their emphasis. Some apparently feel that collecting specimens for science is more destructive than constructive. It is incumbent upon the museum ornithologist, who is aware of the purpose and necessity of scientific collecting, to correct the misconceptions about, and emphasize the need for, the scientific collection ${ }^{1}$ and al so to show the correlation between collecting and conservation. The following remarks are presented in this spirit.

Surely we can assume that any objection to collecting birds does not arise from a prejudice against adding to knowledge. Possibly some people believe that collecting birds has a significant effect on population numbers. There are statistics that disprove this. Lincoln (Auk, vol. 48, p. 540) presents a list of the known causes of death among banded birds, giving the agencies in the order of frequency. Next to the bottom, immediately before miscellaneous causes which includes being struck down by golf balls, we find scientific collectors. He shows that this cause of death amounts to .000015 of 1 percent of all known causes and we can be sure that all such cases were reported.

There is still another factor which enters into the matter of objection to collecting. This is human emotion, and this is understandable. It is my belief that the capacity for emotion is one of the highest of human attributes but I also believe that the capacity to control one's emotions is higher.

To be brief, I have tabulated below a number of statements intended to reveal the purpose and effect of collecting with special reference to birds.

1st. Collecting specimens is simply a matter of gathering facts to further direct observation. It will never be desirable to cease gathering facts and make direct observation as was done during the Dark Ages.

2nd. Specimens for study and comparison are the special tools of the museum sciences. Although the museum researcher is interested in living organisms, without specimens his particular basis for study (identification, classification, zoogeography, evolution) would not exist, in fact neither would museums.

3rd. Nature is dynamic so that fact-gathering is a continuing process, never completed. Futhermore, all the museums of the world put together would not be a complete collection.

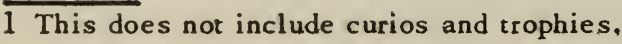


4th. Specimens collected, preserved, labelled, and carefully housed in a research collection are perpetually useful. A research collection is not unlike a library of books or a bureau of standards. Specimens are not expendable in the ordinary sense and can be referred to during the development of new ideas or re-examined for verification or rejection of established concepts.

5th. Collecting birds for research is precisely the same business as collecting butterflies, bullfrogs, or bears, except that it may elicit a different emotional response from some. Ironically, many scientific collectors of birds have been responsible for sharpening the public's emotional regard for birds.

6th. In the history of bird conservation in North America many of the most earnest and effective proponents were, and are, scientific collectors. To mention but a few, we have in Canada the names Taverner, Saunders and Lloyd; in the United States, Chapman, Forbush and Gabrielson. Undoubtedly birds, as well as the study of them, profited from their collecting.

7th. Without the background of knowledge based on collected specimens, no adequate bird protection law could be framed and no authoritative bird book could be written.

8th. Without specimens there could not have been an Audubon as we know him, and ornithological illustrators of our times such as Fuertes, Brooks and Shortt could not have been ornithological illustrators.

9th. In addition to the needs of research and illustration, specimens remain virtually indispensable in teaching, either with a cultural approach or in the training of scientists.

It is presumed that there are people who would endorse the foregoing but would question the value of collecting regional rarities ${ }^{d}$ which excite so much popular interest. This attitude is understandable if we acknowledge that the interest of most bird observers is more pronouncedly stimulated by the unusual. It is also evident that this interest has a value but there is no way of measuring and weighing it against the value of a collected specimen. What are the values of a collected rarity, those extra-limital erratica of the bird world?

a) An erratic collected, labelled and preserved proves beyond all' doubt, both to us and to posterity, that a representative of a given species did occur extralimitally at a certain time. No other evidence is as absolute and the specimen can be referred to again and again. This is the simple demand of science especially when dealing with the unusual.

b) A collected specimen can be weighed and measured; its sex determined by dissection; its age class established; its normalities or abnormalities observed, the latter including starvation, injury, disease, parasites, hybridity and other matters. Such biological data may indicate why the bird occurred extralimitally and critical examination may even indicate whence it came.

1 Vanishing species, such as the whooping crane, are not included in any reference to rare occurrences. The welfare of such species is as much a concern of scientific collectors as anyone else, probably more so. 
c) A specimen taken extralimitally often marks the occasion when some biological event is taking place far away in the heart of range of the species involved. The specimen is simply an undeniable basis for correlation, now or at some time in the future.

d) A regional rarity is not always a waif or stray. It may prove to be a pioneer of range change and thus a collected specimen becomes historically important. Certainly the collecting of a pioneer will not thwart population expansion if it is under way any more than Indian massacres stopped the settlement of this continent.

e) It is well known that many waifs and strays do not survive displacement. A specimen in a research collection will be useful for an estimated thousand years or more. Its remains on a beach or field make small contribution to the scavenger or soil.

It is on these premises that the Department of Ornithology of the Royal Ontario Museum has conducted its work and will continue to do so. To those who may question the judgment exercised in collecting rarities in the Toronto region, I add the following:

When we collect specimens we are doing so under Federal permits issued by a Government Department charged with the conservation of wildlife and this is significant. We weigh the values in every case, dispatch the best marksman and notify the divisional police who render courteous cooperation. The least possible disturbance is created.

Perhaps the following comments will be the most informative of all, to critics of our procedure: Over the past ten years the Museum has collected exactly 13 specimens which would classify as regional rarities, waifs and possible pioneers. One proves the first and only occurence of a species for the whole of Canada. Two represent European species having no breeding outposts in the New World and the chances of the se individuals reaching home would seem slight. Five were hybrids, the living existence of which could have meant nothing to the parent species. Two proved that previous field identification of them by local observers was incorrect. The other three were important for various reasons including sole age and plumage representation for the province.

The Royal Ontario Museum, your museum, invites your understanding. 